\title{
Experimental Study on the Impermeability of Concrete Construction Joints with Different Geometric Shapes
}

\author{
Cheng Zhijun ${ }^{1}$, Li Wenpei ${ }^{2}$, Fan Pengxian ${ }^{1,3, *}$ and Zhang Ning ${ }^{1}$ \\ ${ }^{1}$ State Key Laboratory of Disaster Prevention \& Mitigation of Explosion \& Impact, PLA University of Science and \\ Technology, Nanjing, Jiangsu 210007, China \\ ${ }^{2}$ Engineering Design \& Research Institute of Navy, Institute of Engineering Design and Research, Beijing 100070, China \\ ${ }^{3}$ College of Field Engineering, PLA University of Science and Technology, Nanjing, Jiangsu 210007, China
}

\begin{abstract}
Concrete construction joints are widely used in underground structures. The structure's impermeability is generally considered as its weak point. In this paper, influence of geometric shape and contact slurry on the impermeability of construction joints has been researched by a model test. Three joint types, including flat joints, arc joints and trapezoid joints, were constructed and tested. The tested construction joints were cast by half individually with a determined time interval to simulate the practical construction process. Each joint type has twelve samples, divided averagely into two groups, one of which was smeared by slurry on the contacts and the other was not. Test result shows that the structural type of construction joints has a great influence on the impermeability of samples. Trapezoid joints have the best impermeability, arc joints take the second place and flat joints are the worst. The contact slurry has a considerable unfavorable effect on the impermeability of construction joints.
\end{abstract}

Keywords: Model test; concrete construction joint; impermeability.

\section{INTRODUCTION}

Underground structures have a great requirement for waterproofness because of its complex corrosion surrounding condition [1,2]. The durability of concrete in moist environment has been studied for decades and many publications shown a high-level knowledge of that [3-6]. Generally, the cast-in-place concrete can meet the impermeability requirement. However, the whole structure can not be cast and constructed once for all. Construction joints are unavoidable in the construction of underground structures. The connected part cast at different time provides a pathway for the seepage water, and the existence of construction joints has a great influence on water impermeability of underground structure.

For example, underground diaphram wall is one of the widely used structures in underground basement, parking, street, storehouse, etc. The diaphram wall acts as a seepageproofing barrier and cuts off the groundwater in construction period, and sometimes turns into a permanent part of the underground engineering. Construction joint, as a main constituent part, controls the seepage-proofing performance of underground diaphram wall, which is one of the most important functions both in construction and service period.

The impermeability of concrete joints has been studied by a few researchers. As early as 1967, B D Trinker pointed

*Address correspondence to this author at the No. 88 Houbiaoying Road, Qinhuai District, Nanjing City, 210007, P R China; Tel:+86-025-80822033; Fax:+86-025-80825360; Email:fan-px@139.com out that the life span and reliability of monolithic concrete structures depend heavliy on appropriate methods of placing concrete mixture during construction [7]. He conducted a series of tests to investigate the strength, frost-resistance and impermeability of concrete construction joints, among which more than 50 test-cylinders were used for impermeability test. He found that test-pieces with treated construction joints and with concreting of the second half of the test-piece after 3-14 days, has somewhat lower impermeability.

The I H Wong (1997) introduced some experiences about waterproofness of basements constructed concrete diaphragm walls in Singapore [8]. These basements mainly serve as car parks, shops and civil defense shelters. Nearly all the basements in Singapore constructed of diaphragm walls have experienced problems with wetness on or moisture ingress through the walls. He proposed several methods, such as building a false wall and drain cavity, using additives and grouting, but none of them can solve the seepage problem fundamentally.

Chen X X first put forward a new test method for studying water impermeability of concrete construction joints with different shapes, and measured the impermeability pressure of arc joints and trapezoid joints [9]. But his test results had two disadvantages. One is the sample size of the reported test was too small (12 samples in total), and thus the representativeness of the test result is questioned. And the other is the slurry used in the tests was not identical to that used in the slurry (fluid-filled) trench method. 
There are several other literatures which reported some experimental researches on the permeability or impermeability of concrete joints or contacts. In literatures [10-13], the impermeability of flat joints under different conditions was investigated. Shin Y J [14] measured the permeability of placing joint of cement mortar and investigated the influence of temperature and relative humidity. However, few literatures about the influence of joint shape on the impermeability behavior are found, except for the test method presented by Xu H F [15].

Since construction joints can significantly reduce the impermeability of monolithic concrete structure, the engineers engaged in designing and constructing of underground structures have a pressing requirement to know how to enhance the impermeability of joints. Adopting concrete joints with non-planar shape is an effective and economical method. The joggle joints with different geometric shape have already been adopted in prefabricated structural element of diaphram wall. However, the impermeability of them has not been quantitative evaluated, at least, not published.

In this paper, model test has been conducted to investigate the influence of geometric shape and contact slurry on the impermeability of concrete joints. Six groups of samples are manufactured and tested, including flat joints, arc joints and trapezoid joints. Each type of joints has two sample groups, one group is smeared with slurry on the contact, and the other is not. There are six samples in each group. The tests are conducted on concrete impermeability apparatus according to Chinese National Standard GB/T50082-2009 [16]. Test results show that the geometric shape has a great influence on the impermeability of concrete joints and the slurry has a considerable unfavorable affect on the impermeability.

\section{EXPERIMENTAL METHOD}

\subsection{Experimental Design and the Aims}

Trapezoid joints and arc joints are the commonest nonplanar joints. It can be deduced by common sense that the non-planar joints tend to have better impermeability. However, the quantitative estimation of such improvement and which one of the three joint types has the best impermeability are still need to be clarified.

In the practice of underground structure construction, concrete diaphragm walls are frequently constructed in slurry filled trenches. The slurry used to protect the trench wall from collapsing has a great probability staining or even coating the joint contact, and thus affects the impermeability of joints.

In this paper, model tests have been conducted to investigate the impermeability performance of concrete joints with different geometric shapes and interface conditions. The test results is expected to show what kind of joint has the best impermeability performance, and to what degree the slurry affect the impermeability performance of joints.

The impermeability test method presented by Chen X X and $\mathrm{Xu} \mathrm{H} \mathrm{F}$ are adopted and modified to conduct the following tests. In order to simulate the real state of construction joints of the underground structure, the tested samples were cast half by half individually, with a determined time interval. The conducted joint model test is easy and inexpensive.

\subsection{Material and the Manufacture of Test Models}

Three different classical types of construction joints have been constructed for test, including flat joints, arc joints and trapezoid joints. Each type of joint has 12 samples, divided averagely into two sets. One set of samples is smeared by slurry on contacts, and the other set is not. The slurry used in the tests is identical to the one used in the construction of trench, which is composed of water, swell soil, and additives.

The samples used in the model tests are the standard samples for concrete impermeability test except for the presence of the construction joints. The geometric sizes of joints are: top diameter $175 \mathrm{~mm}$, bottom diameter $185 \mathrm{~mm}$, and height $150 \mathrm{~mm}$, whose detailed dimensions are shown as Fig. (1). The seam of flat joint is a beeline which equally divides the tested samples.

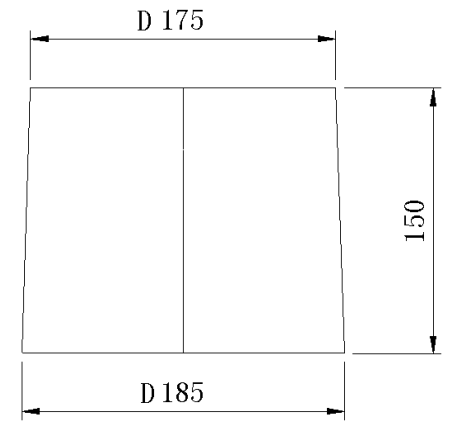

a. flat joints

D 175

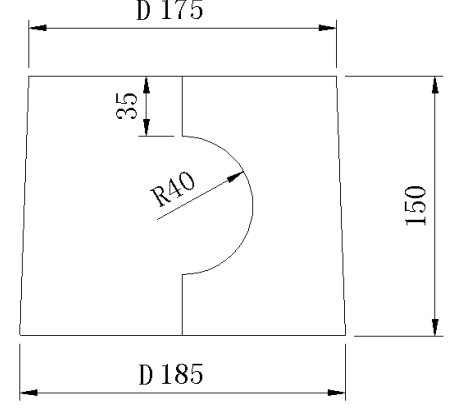

b. arc joints

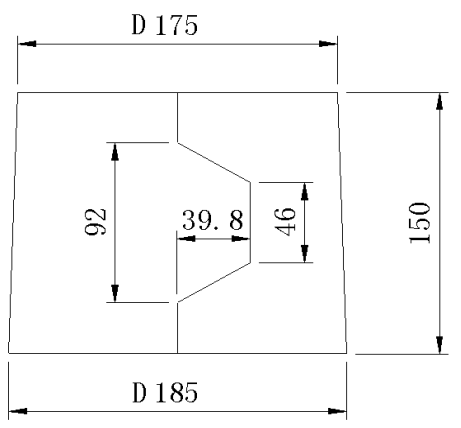

c. trapezoid joints

Fig. (1). The cross section of samples (unit mm). 
The lengths of seepage pathway of arc and trapezoidal joints are designed to be approximately equal to each other. Fig. (2) demonstrates the wooden models of trapezoid joint and arc joint, which are made according to the aforementioned design.

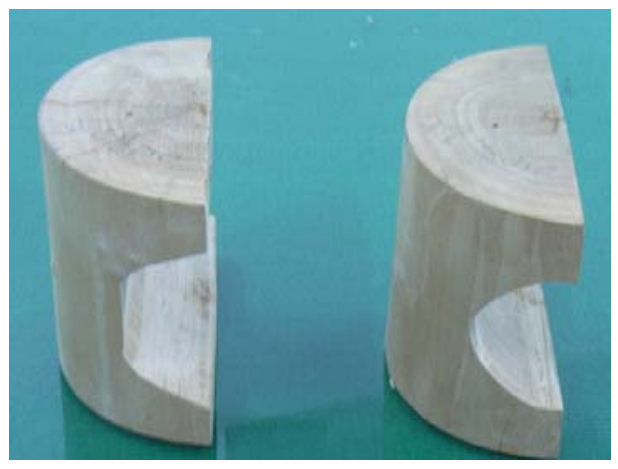

Fig. (2). Wooden models of trapezoid and arc joints

The strength grade of concrete used is C30, while the impermeability grade is S6.

The casting of concrete samples is composed of two steps. In the first step, the steel mould was filled with a wooden model, which occupies one half (not exactly) room of the mould. And then concrete was cast in the other half of steel mould, which was demolded one week later. After one month, the wood model was fetched out and the left half concrete joint was casted in. The samples are cured under standard moist condition for 28 days. In order to avoid the separation and slippage of the seam during the demolding, maintaining and transporting of the samples, a few steel bars or steel nails are used to connect the two half of the samples in constructed process, as shown in Fig. (3).

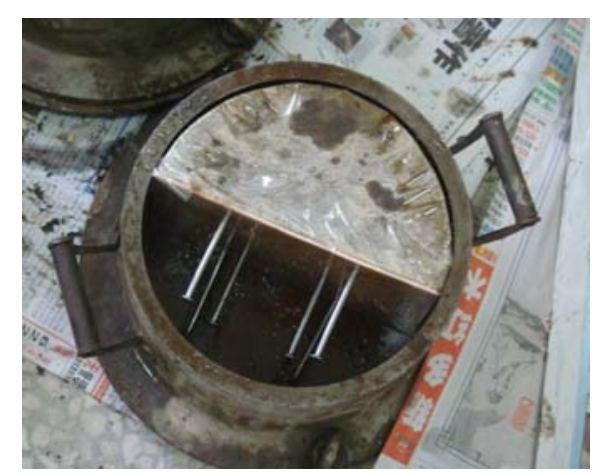

Fig. (3). Sketch of wooden model in steel mould.

\subsection{Test Approach}

The tests were conducted according to the following procedure.

Firstly, take the samples out of the curing room one day before test, wipe water on the surface of the samples, dry them in air, scrape the head faces to keep them clean, daub the side face with a layer of seal material, and then put it immediately into the steel mold of the pressure device.
Secondly, install the samples enclosed in steel mold on the concrete impermeability apparatuses, one set (six samples) each time. The apparatus should be checked before the installation of samples. Before the test, the air in the base of concrete impermeability apparatuses must be excluded by adding water.

Thirdly, turn on the concrete impermeability apparatus and load hydraulic pressure, which begins with $0.1 \mathrm{MPa}$ and then increases $0.1 \mathrm{MPa}$ every $8 \mathrm{~h}$, observe the seepage state of head faces of the samples, stop the test and reseal samples if the water seeps from circumambience of the samples.

Lastly, close the penstock corresponding to the already seeped piece and record the hydraulic pressure at the time when seepage appears on the head face, terminate the test until all six samples seeping.

Two different methods are adopted to analyze the test results. The first is impermeability grade formulation, which is a conventional way. The other is mathematical statistical method, which study impermeability of the samples through computing expectation and mean square deviation of impermeability pressure.

Impermeability grade is calculated according to the impermeability pressure. The expression is:

$S=10 H-1$

in which $S$ is the impermeability grade, $H$ stands for the impermeability pressure when the third of the six samples starts to seep. The unit is MPa.

\section{RESULTS AND DISCUSSION}

\subsection{Raw Results}

The samples are marked according to the follow rules: character $\mathrm{P}$ denotes the flat joint samples, while $\mathrm{H}$ and $\mathrm{T}$ denote the arc joint samples and the trapezoid joint samples, respectively; and character $M$ represents the samples which are smeared by slurry on the contact.

\subsubsection{Flat Joints}

Fig. (4a) gives the seepage state of the flat joint samples with slurry on the contact after tests. The samples with contact slurry seeped in succession when hydraulic pressure began to load. Water leaked from the seam quickly and covered the head face of samples in a short time. The seepage behaviour of joints improved a lot under the absence of slurry. Two samples (P-2 and P-4) began to leak at the beginning of the hydraulic pressure loading. The leakages developed quickly along the flat seam. About half an hour later, another two samples (P-5 and P-6) started to seep. The seepage of sample P-5 was comparatively obvious and continued along the entire seam. The seepage of sample P-6 was small, and located at the corner of sample seam. The last two samples (P-1 and P-3) seeped when hydraulic pressure rose up to $0.2 \mathrm{MPa}$. Fig. (4b) is the picture of seepage state of the flat joint samples without slurry at $0.2 \mathrm{MPa}$ hydraulic pressure.

The test results statistics of the flat joints without slurry is presented in Table $\mathbf{1}$. 
Table 1. Test Results of Flat Joints Without Slurry

\begin{tabular}{|c|c|c|c|c|c|c|}
\hline Hydraulic Pressure (MPa) & P-1 & P-2 & P-3 & P-4 & P-5 & P-6 \\
\hline \hline 0.1 & No & Yes & No & Yes & Yes & Yes \\
\hline 0.2 & Yes & & Yes & & \\
\hline
\end{tabular}

'Yes' and 'No' denote leakage happen or not, respectively.

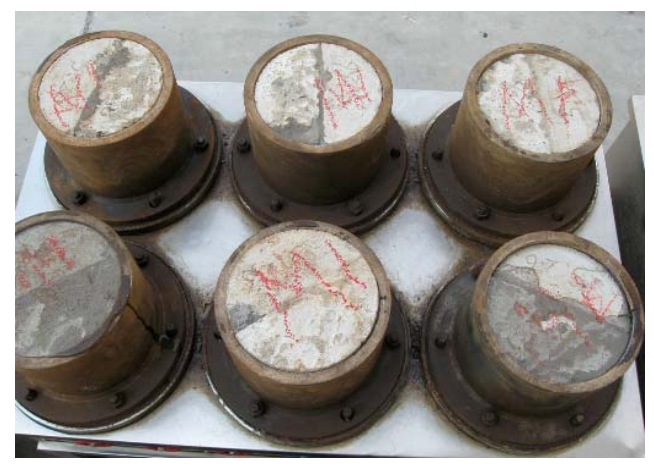

a. with slurry

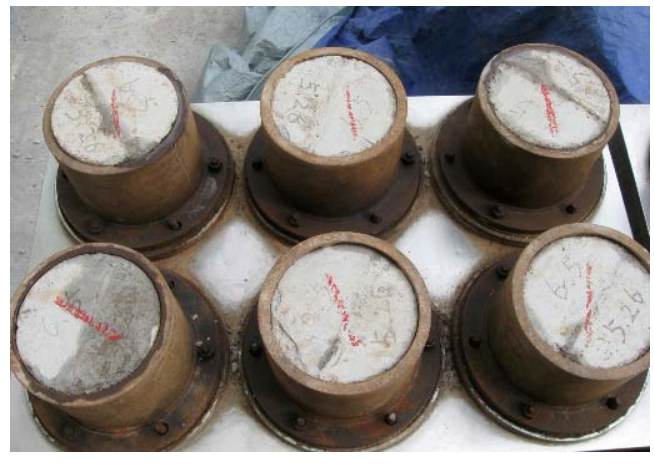

b. without slurry (0.2MPa)

Fig. (4). Seepage state of the flat joints.

\subsubsection{Arc Joints}

The seepage state of the arc joints with slurry was similar to the results of flat joints. In the test of arc joints without slurry, sample $\mathrm{H}-5$ began to leak quickly once the hydraulic pressure is loaded. It implies that sample $\mathrm{H}-5$ is an unqualified sample for its impermeability is far below the average. Thus, $\mathrm{H}-5$ is removed from test results. Table 2 presents the test result statistics of arc joints without slurry.

\subsubsection{Trapezoid Joints}

Similar to the first two groups, the trapezoid joints with slurry have poor seepage-proofing performances. The samples leaked successively when hydraulic pressure started to load. To the contrary, the trapezoid joint samples without slurry can bear relatively high hydraulic pressure. The samples began to leak (T-1) when hydraulic pressure was higher than 0.3MPa and the seepages were all along sample seams. When hydraulic pressure got up to $0.6 \mathrm{MPa}$, the last two samples (T-2 and T-3) began to leak. Sample T-2 seeped along all the length of seam, while the seepage of block T-3 developed from one point. Table 3 presents the test result statistics of the trapezoid joints without slurry.

\subsection{The Influence of Slurry}

From the test results, it is apparent that all samples with slurry, no matter flat, arc or trapezoid, have poor seepageproofing performances. Once hydraulic pressure is loaded,

Table 2. Test Results of Arc Joints Without Slurry

\begin{tabular}{|c|c|c|c|c|c|c|}
\hline Hydraulic Pressure (MPa) & H-1 & H-2 & H-3 & H-4 & H-5 & H-6 \\
\hline \hline 0.1 & No & No & No & No & Yes & No \\
\hline 0.2 & No & No & Yes & Yes & No \\
\hline 0.3 & Yes & No & & & Yes \\
\hline 0.4 & & Yes & & & \\
\hline
\end{tabular}

Table 3. Test Results of Trapezoid Joints Without Slurry

\begin{tabular}{|c|c|c|c|c|c|c|}
\hline Hydraulic Pressure (MPa) & T-1 & T-2 & T-3 & T-4 & T-5 & No \\
\hline \hline 0.1 & No & No & No & No & No \\
\hline 0.2 & No & No & No & No & No \\
\hline 0.3 & Yes & No & No & No & No \\
\hline 0.4 & & No & No & No & Yes \\
\hline 0.5 & & No & No & Yes \\
\hline 0.6 & & Yes & Yes & & \\
\hline
\end{tabular}


almost all samples with slurry began to leak immediately and the residual samples also seeped in a few minutes. The seepages were obvious, generally covered the head faces of samples in short time.

According to the test results, samples with slurry of all the three types of joints can not bear the hydraulic pressure greater than $0.1 \mathrm{MPa}$. Test results indicate that the samples with slurry on construction joints have almost no impermeability. Therefore, the presence of slurry severely reduces the impermeability of joints.

\subsection{Mathematical Statistics of Test Results Without Slurry}

Statistics obtained from the flat joint test without slurry indicate that four samples seeped at $0.1 \mathrm{MPa}$, and the other two samples leaked at $0.2 \mathrm{MPa}$. The samples of flat joint without slurry have rather poor impermeability. The impermeability pressure is $0.1 \mathrm{MPa}$. The impermeability grade of flat joints without slurry, computed by formula (1), is S0. Table 4 presents mathematical statistical results of the flat joints without slurry.

Table 5 gives the test result statistics of the arc joints without slurry. Sample H-5 has some quality problems in the constructed process, which are eliminated from the results. From Table 2, two samples begin to leak at $0.2 \mathrm{MPa}$. When hydraulic pressure reaches $0.3 \mathrm{MPa}$, another two samples seeped. The last sample leaked when hydraulic pressure arrives at $0.4 \mathrm{MPa}$. According to such comprehensive evaluation, the samples of arc joint without slurry can bear $0.3 \mathrm{MPa}$ hydraulic pressure. The impermeability grade of the tested arc joints without slurry is S2. Table $\mathbf{5}$ gives mathematical statistical results of the arc joints without slurry.

The statistics from trapezoid joints test result without slurry are presented in Table $\mathbf{6}$, which shows that the first sample leaked at $0.3 \mathrm{MPa}$ hydraulic pressure. There was one sample seeped at $0.4 \mathrm{MPa}$. Another two samples seeped when hydraulic pressure reaches $0.5 \mathrm{MPa}$. The last two samples leaked at $0.6 \mathrm{MPa}$ finally. The tested trapezoid joints without slurry have relative higher impermeability than the other two types of joints. The impermeability grade of the tested trapezoid joints without slurry is S4.
For clearness, Fig. (5) demonstrates the leakage distribution of the samples without slurry.
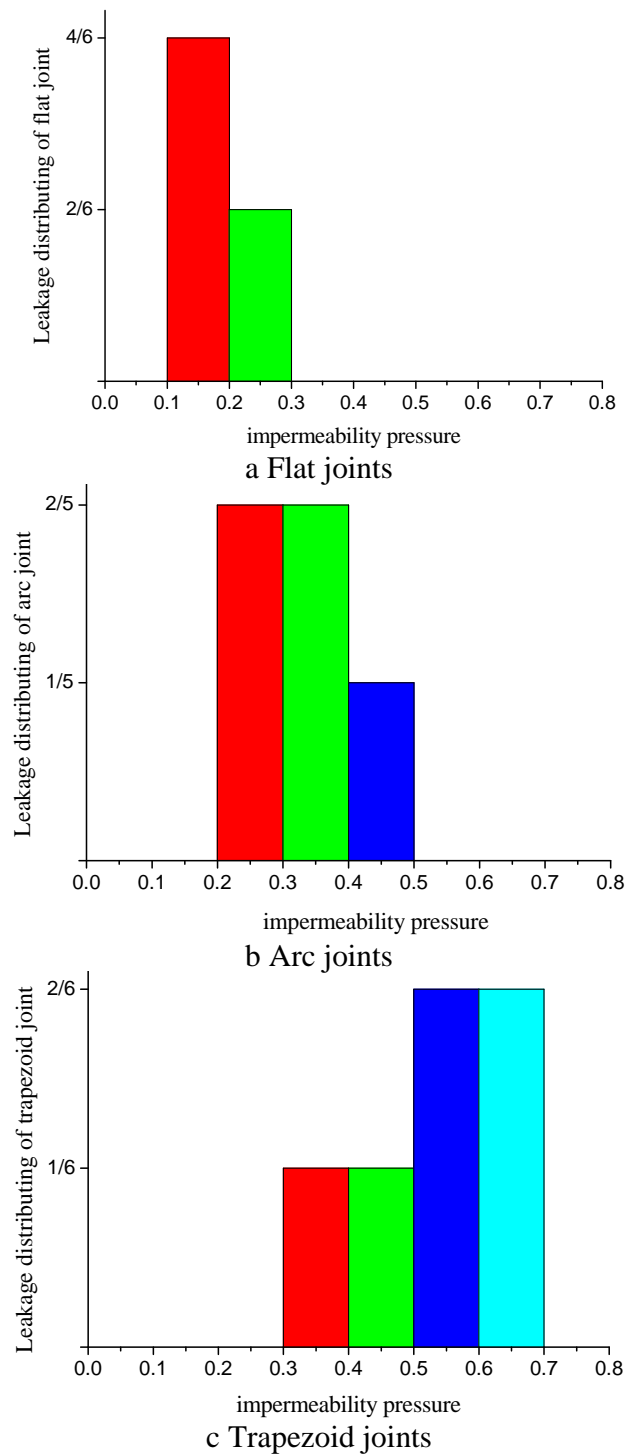

Fig. (5). Leakage distributing charts of the groups without slurry.

Table 4. Mathematical Statistics of Flat Joints Test

\begin{tabular}{|c|c|c|c|c|}
\hline Hydraulic Pressure(MPa) & $\mathbf{0 . 1}$ & $\mathbf{0 . 2}$ & Expectation & Mean Square Deviation \\
\hline \hline leakage probability & $4 / 6$ & $2 / 6$ & 0.13 & 0.047 \\
\hline
\end{tabular}

Table 5. Mathematical Statistics of Arc Joints Test

\begin{tabular}{|c|c|c|c|c|c|c|}
\hline Hydraulic Pressure (MPa) & $\mathbf{0 . 1}$ & $\mathbf{0 . 2}$ & $\mathbf{0 . 3}$ & $\mathbf{0 . 4}$ & Expectation & Mean Square Deviation \\
\hline \hline Leakage probability & 0 & $2 / 5$ & $2 / 5$ & $1 / 5$ & 0.28 & 0.075 \\
\hline
\end{tabular}

Table 6. Mathematical Statistics of Trapezoid Joints Test

\begin{tabular}{|c|c|c|c|c|c|c|c|c|}
\hline Hydraulic Pressure (MPa) & $\mathbf{0 . 1}$ & $\mathbf{0 . 2}$ & $\mathbf{0 . 3}$ & $\mathbf{0 . 4}$ & $\mathbf{0 . 5}$ & $\mathbf{0 . 6}$ & Expectation & Mean Square Deviation \\
\hline \hline Leakage probability & 0 & 0 & $1 / 6$ & $1 / 6$ & $2 / 6$ & $2 / 6$ & 0.48 & 0.112 \\
\hline
\end{tabular}


Table 7 gives the impermeability pressure and the impermeability grades of the three types of concrete construction joints without slurry. As shown in Table 7, the impermeability grades of flat joints, arc joints and trapezoid joints are S0, S2 and S4, respectively.

From Table 7, we can obtain some knowledge about the influence of geometric shape on the impermeability performance of joints. Leakage expectation of flat joints is higher than impermeability pressure, while for arc joints and trapezoid joints are relevantly lower than impermeability pressure. The analysis results obtained by the two different methods are similar in total. The geometric shape of joints has great influence on the impermeability performance of joints, and controls the waterproofness performance of underground structures to a certain extent.

According to the test results, trapezoid joints is the joint structure with the best impermeability performance, arc joints takes the second place and flat joints is the worst.

\subsection{Discussions}

\subsubsection{The Influence of Geometric Shape}

In order to reveal the path of infiltration water, $\mathrm{Xu} \mathrm{H} \mathrm{F}$ [15] cut open several tested samples. He declared that the arc joint is more conducive to infiltrating without discussion.

The typical vertical sections of joints after seepage is shown as Fig. (6). In Fig. (6), the black solid lines represent the interfaces of joints, and the dark area enclosed by dash lines are infiltrated by water. From Fig. (6a), one can see that the water seepages by and large along the interface, and the arc joint serves as a passageway for water to some extent. However, in Fig. (6b), the water seepage is less affected by the interface. It is obvious that the angular turnings usually serve as water shut-off by the analysis of the vertical sections of joints. Therefore the trapezoid joint has better impermeability for its greater quantity of angular turnings.

The impermeability grades of all the tested samples, with or without slurry, are smaller than the impermeability grade of concrete, which is S6. This fact implies that the presence of joints reduces the impermeability of the structures, which means that the impermeability of the structures is controlled by the impermeability of the joints.

It is notable that the arc joints, which are widely used in underground diaphram walls, have an unsatisfactory impermeability. The impermeability of arc joints is obviously lower than that of the trapezoid joints. According to the test results, trapezoid joints are preferable for impermeability consideration.

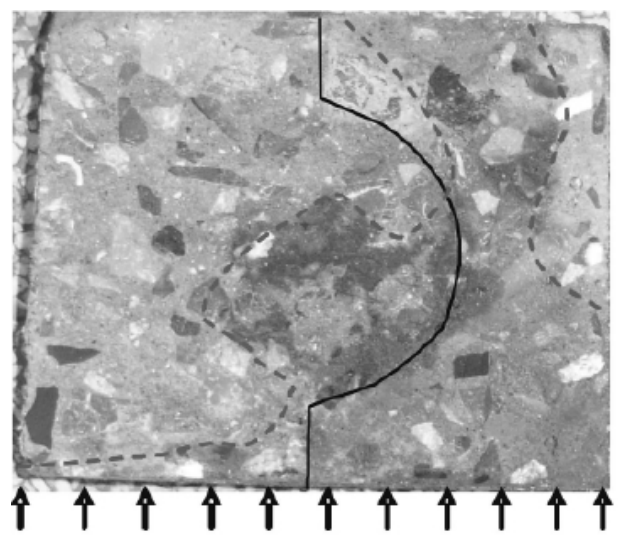

a. arc joint

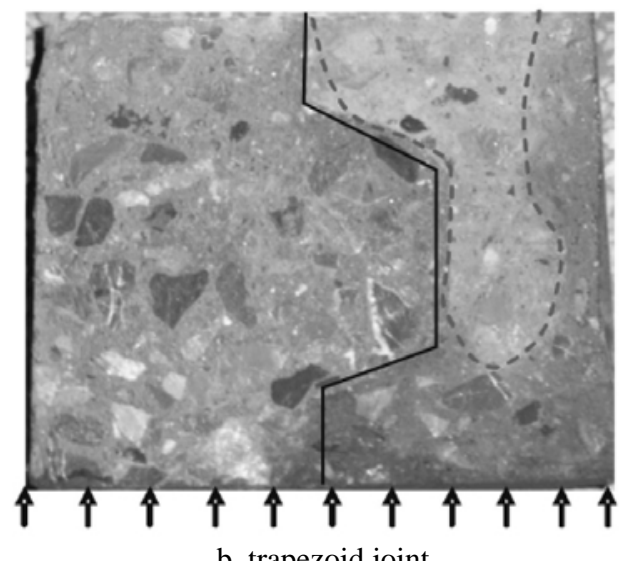

b. trapezoid joint

Fig. (6). The vertical section of tested samples.

\subsubsection{The Role Slurry Plays}

The influence of slurry on the impermeability of joints can be obtained by the comparison of the test results of groups with and without slurry. Apparently, the impermeability of the samples with slurry are much lower than the samples without slurry, no matter the joints shape is flat, arc or trapezoid. The presence of slurry on the joint interface has a considerable unfavorable effect on the impermeability of joints. Slurry is frequently used to prevent the sidewall of trench from collapsing. If the construction quality is not controlled with care, slurry is likely to stain the contact of joints in the constructing and severely reduce the impermeability of underground structures. It is very important to keep the joint contact clean for impermeability consideration.

Table 7. Test Results of Joints Without Slurry

\begin{tabular}{|c|c|c|c|}
\hline Joint Shape & Flat & Arc & Trapezoid \\
\hline \hline Impermeability pressure (MPa) & 0.1 & 0.3 & 0.5 \\
\hline Impermeability grade & S0 S2 & S4 & 0.28 \\
\hline Leakage expectation (MPa) & 0.13 & 0.075 & 0.112 \\
\hline Mean square deviation & 0.047 & S \\
\hline
\end{tabular}




\section{CONCLUSIONS}

The impermeability of concrete joints is very important to the performance of underground structures. In order to investigate the influence factors of impermeability, twelve groups of joints are constructed and tested. The influence of geometric shape (flat, arc and trapezoid) and the presence of slurry (with and without) are investigated. From the analysis of test results, conclusion has been drawn as follows:

(1) The geometric shape significantly influences the impermeability of concrete construction joints.

(2) Trapezoid joints have the best impermeability, arc joints take the second place and flat joints are the worst. The trapezoid joints are recommended to replace the commonly used arc joints in order to improve the impermeability of concrete construction joints.

(3) The presence of slurry on the interface of joints has a considerable unfavorable effect on the impermeability of joints, which should be controlled with care in the constructing of underground structures.

\section{CONFLICT OF INTEREST}

The authors confirm that this article content has no conflicts of interest.

\section{ACKNOWLEDGEMENT}

The authors gratefully acknowledge the financial support from the National Key Basic Research Program of China (Grant: 2013CB036005) and the Science Fund for Creative Research Group of the National Natural Science Foundation of China (Grant: 510210001).

\section{REFERENCES}

[1] R. E. Melchers, "The effect of corrosion on the structural reliability of steel offshore structures”, Corros. Sci., vol. 47, pp. 2391-2410, 2005.
[2] S. Ahmad, "Reinforcement corrosion in concrete structures, its monitoring and service life prediction-a review", Cement. Concrete. Comp.; vol. 25, pp. 459-471, 2003.

[3] R. Vedalakshmi, K. Rajagopal, and N. Palaniswamy, "Longterm corrosion performance of rebar embedded in blended cement concrete under macro cell corrosion condition”, Constr. Build. Mater., vol. 22, pp. 186-199, 2008.

[4] X. F. Song, J. F. Wei, and T. S. He. b, “A method to repair concrete leakage through cracks by synthesizing super-absorbent resin in situ”, Constr. Build. Mater., vol. 23, pp. 386-391, 2009.

[5] M. Jooss, and H. W. Reinhardt. "Permeability and diffusivity of concrete as function of temperature”, Cement. Concrete. Res., vol. 32, pp. 1497-1504, 2002.

[6] Y. Wen-wu, Q. Jue-shi and Z. Yi-Ying, "Effect of Fly Ash on Frost-Resistance and Chloride Ions Diffusion Properties of Marine Concrete”, Chn. Undergr. Eng., vol. 23, pp. 367-377, 2009.

[7] B. D. Trinker, "Investigation of Strength, Frost-resistance and Impermeability of Concrete Construction Joints", Translated from Gidrotekhnicheskoe Stroitel'stvo, vol. 9, pp. 20-22, 1967.

[8] I H. Wong "Experience with Waterproofness of Basements Constructed of Concrete Diaphragm Walls in Singapore”, Tunnelling. Undergr. Space Technol, vol. 12, no. 4, pp. 491-495, 1997.

[9] X. X. Chen "Study on Technology and Theory of Assembled Periphery Partition Wall of Surrounding Structure for Civil Air Defence", M.S. Thesis, PLA University of Science and Technology, Nanjing, China, 2008.

[10] D. Y. Gao, H. Q. Cheng, and H. Feng, "Permeability of Bonding Interface between New Steel Fiber Reinforced Concrete and Existing Concrete”, J. Hydroelectr. Eng., vol. 28, no.1. pp. 152-158, 2009. (in Chinese with English abstract)

[11] H. Yao, and X. G. Wang, "Experimental Research on Permeability of Steel Fibre-old Concrete Bonding Interface”, Concrete, vol. 9, pp. 21-24, 2009. (in Chinese with English abstract)

[12] Q. Yuan, C. Y. Ma, and Z. K. Li, "Experimental Research on Impermeability of Cold Joints”, Concrete, vol. 9, pp. 10-11, 2008.(in Chinese with English abstract)

[13] M. Frigione, MA Aiello, and C Naddeo. "Water effects on the bond strength of concrete/concrete adhesive joints", Constr. Build. Mater., vol. 20, pp. 957-970, 2006.

[14] Y. J. Shin, T. Kyoji, and M. Hiroyuki. "Effect of ambient temperature and humidity on permeability of placing joint of mortar in casting”, J. Struct. Constr. Eng. (Trans. AIJ). no. 567, pp.13-18, 2003.

[15] X. Hong-Fa, Y. Kai-yang, C. Xue-xin, and L. Wen-pei1, "Method of Impermeability Test of Concrete Joints", J. Sichuan Univ., vol. 42, no. 4, pp.7-12, 2010.

[16] National Standard GB/T50082-2009, "Standard for test methods of long-term performance and durability of ordinary concrete", Beijing, China, 2009.

\section{Received: November 09, 2012

